\title{
Progress in Double Cropping System of Sorghum in Ethiopia: A Review Article
}

\author{
Tamirat Bejiga*, Temesgen Teressa \\ Melkassa Agricultural Research Center, P.O Box 436, Adama, Ethiopia
}

*Corresponding Authors: Tamirat Bejiga, Melkassa Agricultural Research Center, P.O Box 436, Adama, Ethiopia

\begin{abstract}
Improved sorghum management practice and cropping systems can offer smallholder farmers with constancy in their household nutritional needs. Double-cropping is an arrangement of farming a second crop is planting in the same farm field after the harvest of the first crop.This review examines the possibility of application of a double cropping system of sorghum. Double cropping system can increase environmental advantage and provide additional income to farmers by producing yield two times in the same season in the same field. Double crops protect soil against wind and water erosion and increase land use efficiency. For instance, when sorghum is grownafter mung bean or other pulses, one it has economic benefit by increasing income on the other hand, it has advantages of improving soil fertility specifically, in nitrogen fixing to reduce money expenses, to purchase farm inputs such as fertilizer. So, double cropping system should be encouraged in the Ethiopia where, farmers are following subsistence farming only. Mainly, Kobo (North Wollo) in Amhara region, Babile (East Hararghe) and Mieso (West Hararghe) of Oromia regions are known for their bimodal rain fall distribution patterns and are favourable to expand the sorghum double cropping system.
\end{abstract}

Keywords: Double cropping, Sorghum, Mung bean, Environment, Ethiopia

\section{INTRODUCTION}

The greatest essential strategy to increase agricultural production is the development of new high intensity cropping system, which is tolerant to biotic and abiotic stresses (Kinde et al., 2015). Agricultural productivity is at risk from risky weather and upcoming climate change (Christina and Jacob, 2016). Agriculture and cropping system found all over the world are the outcomes of difference in local climate, soil type, and a range of socio-economic and biological factor that are influence the crops to grow and cropping system exist (Kinde et al., 2015).

Sorghum is adjusted to differentclimate patterns and is forecast to sustain widespread fitness across various places of climatic zones under weather change (Christina and Jacob, 2016). Sorghum is an essential part of the diverse crop-livestock farming system in the drought environments of Ethiopia. These areas are mostly known by poor farming practices such as mono cropping and absence of nitrogen fertilizer use. In such situations, better crop management practices and varieties can be an important role to sorghum farmers, well-being in Ethiopia (Alemu, 2018). For the reason, as an essential grain, improved sorghum management can deliver smallholder farmers with stability in their household nutritional needs (Christina and Jacob, 2016). A wide range of sorghum germplasm is existing for the diverse environments and purposes in Ethiopia (Alemu, 2018).

Double cropping is the harvest of two crops from the same field in a single calendar year (Borchers $e t$ al., 2014). Double cropping system is interesting worldwide attentions both in developed and in developing countries (Kinde et al., 2015). It will also advantageous for the increase of annual production (Koji et al., 2016). Farmers would have improved demand for their products, double cropping would guarantee the land was not bare and exposed to erosive forces between crops (Moore and Karlen, 2013). However, the economic return per unit area and time are the main considerations for acceptances of a certain cropping system and yield is the primary agronomic parameter in any category of cropping system (Kinde et al., 2015). Increased biomass crop production is essential for the development of sustainable bioenergy and bioproduct industries (Moore and Karlen, 2013). This review objectives to investigate the possibility of application of a double cropping system of sorghum in Ethiopia. 


\section{Double Cropping Systems}

The cropping system is well-defined as the grouping of crops grown on a specified area within year (Kinde et al., 2015). Double cropping is one practice in a set of practices known as multi-cropping. Multi-cropping includes numerous ways farmers can use one piece of land in a single growing season. Double cropping is one method of rise to expand production and potentially increase the return to farming is by increasing the use of existing growing areas (Borchers et al., 2014).

In the moisture stress bimodal rainfall distribution environments of Ethiopia, sorghum is an integral part of a mixed crop-livestock farming system. These locations are mostly characterised poor agricultural practices such as monocropping system (Alemu, 2018). The rationale for double cropping is to well exploit the cultivating season by using a sequence of crops that are better adapted to specific growing periods within a season (Moore and Karlen, 2013). Grain sorghum can also be double cropped after small grain (Thomason et al., 2017). The most practicable approach to double cropping bioenergy crops would take in growing two biomass crops grown in succession (Moore and Karlen, 2013).

The limitations of double cropping increase at higher latitudes because of a more contracted growing season. Unpredictable fall and spring weather often interferes with planting and harvest, and then increases risk associated with producing either crop (Moore and Karlen, 2013). Soil fertility, temperature and length of rainy season influence the kind of cropping systems (Kinde et al., 2015).

\subsection{Double Cropping Sorghum for Grain Yield Production}

Grain sorghum was effectively produced in both full season and double-crop settings (Thomason et al., 2017). The planting date and maturing time are significant factors influencing crop output of the system under a given location (Can and Yoshida, 1999). Soybean and grain sorghum can be positively cultivated both full season and double-cropped after small grain. Double-crop sorghum yields were comparable when grown after either wheat or barley. Yields and overall achievement depends heavily on local weather, especially rainfall patterns (Thomason et al., 2017). Farmers in moisture stress areas of East Hararghe Zone of Fedis district have been practicing mono cropping of sorghum for a long time which is late in maturity taking 7-8 months. Mono cropping does not guarantee the production of satisfactory food for the family (Fuad et al., 2017). Early maturity is necessary traits of the cultivars for double cropping system (Can and Yoshida,1999). The use of late flowering variety or delayed sowing may not decrease the grain yield of the spring crop, but may decrease the yield of the fall crop by suspending the harvest in fall season. In summer sowing, late flowering or late planting is frequently related with ill developed grains and may decrease grain yield due to the low temperature during the grain filling period (Can and Yoshida, 1999).

\subsection{Double Cropping Sorghum for Biomass Production}

Double crop biomass production is a comparatively new focus for agriculture in the north central USA, driven by the need to offer lignocellulosic feedstocks for bioenergy plants and not disordered with former studies on double cropping for grain production (Moore and Karlen, 2013).

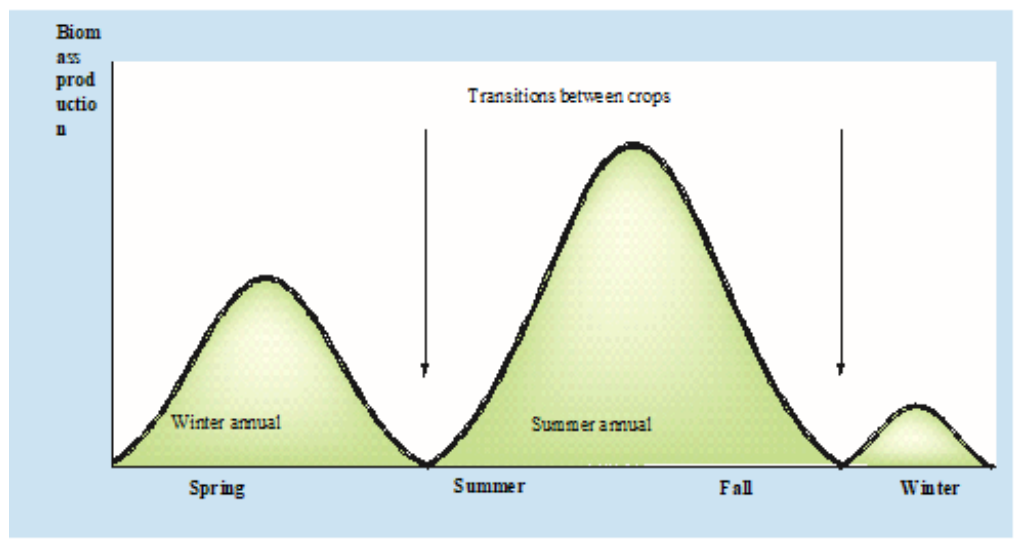

Source: Moore and Karlen, 2013.

Figure1. Biomass production for a double-crop sequence using a winter annual crop followed by a summer annual crop to extend the growing season and duration of soil cover. 
Approach for addressing the multiple competing forces is to practice a landscape-scale management approach that concurrently examines not only the global want for renewable biofuels and the many strong economic and social drivers related with it (Wilhelm et al., 2010).

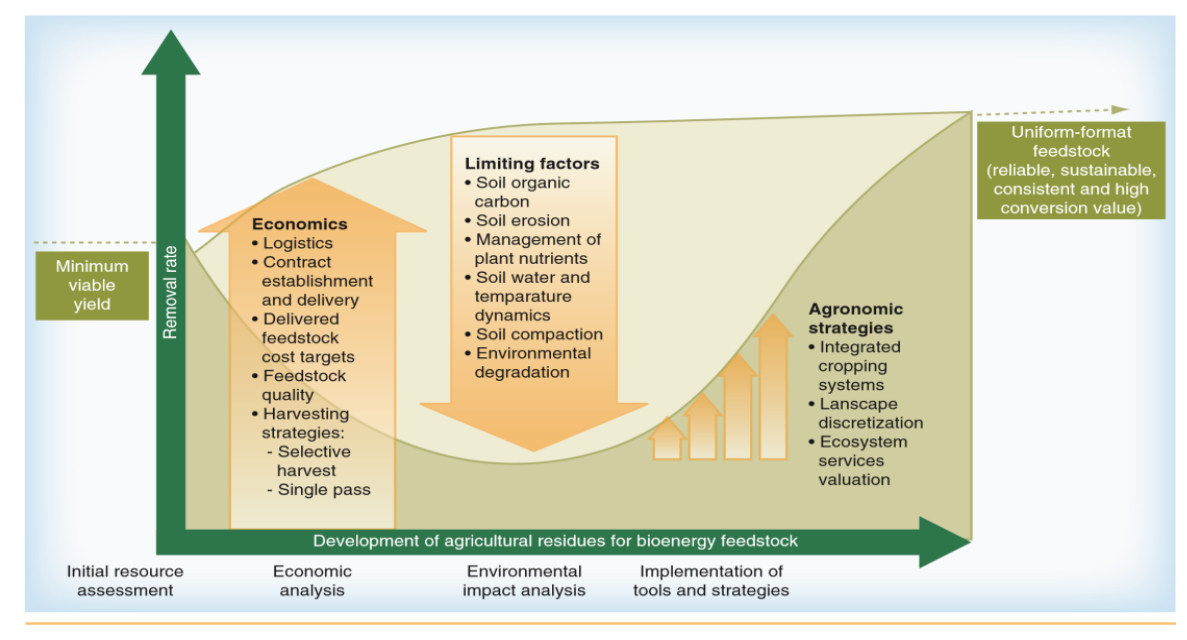

Source: Wilhelm et al., 2010

Figure2. A competing economic and environmental sustainability forces that must be well-adjusted to attain sustainable cellulosic feedstock supplies that will support the transition from fossil to renewable fuels

\subsection{Environment and Economic Benefit of Double Cropping}

Double cropping of bioenergy feedstock crops has the potential to become a significant soil and crop management approach for concurrently improving soil quality and producing biomass feedstocks (Moore and Karlen, 2013). The nutrient amendment is a significant cost for African smallholder farmers (Christina and Jacob, 2016). Equating the net profit of applying the nutrient management systems for outline circumstances under which a given amendment strategy is possible and favorable is mandatory for determine the best methods for nutrient amendment. During periods of vigorous plant growth biomass crops aggressively cycle nutrients from the soil to support new growth. Nutrients that are moveable in the soil, such as nitrate, are immobilized as they are incorporated into the growing plant (Moore and Karlen, 2013).

Lignocellulosic biomass crops do not need to whole their lifecycle and produce seed, double cropping those species could be effective and offer several beneficial ecosystem services. This includes providing almost perennial ground cover to decrease soil exposure to water and wind erosion, and varying landscapes. Double cropping could also offer management flexibility in response to climate and market factors (Moore and Karlen, 2013). However, in other way, double cropping may need extra inputs, such as pesticides, herbicides, fertilizer, irrigation water, or use of conventional tillage, which can have undesirable environmental impacts (Borcherset al., 2014).

Legume rotation affords a source of protein rich grain, recovers soil nutrients, decreasing the need for inorganic Nitrogen fertilizer frequently, and has been verified to control Striga infestation (Christina and Jacob, 2016). Yields of double cropped rye and sorghum were enhanced when included in a 3year rotation with corn and soybean. Use of a double crop system more real in increasing biomass yield as part of a longer rotation that consists of soybean or alternative legume (Moore and Karlen, 2013). Numerous nutrient amendment methods meaningfully improve sorghum yield. Sorghum is an imperative grain to deliberate for reducing risk under climatic uncertainty (Christina and Jacob, 2016).

Economic profits of double cropping contain the potential of additional income from a second crop on the same land base. To expand production and potentially increase the economic returns to farming is to intensify the use of existing crop land (Borchers et al., 2014). Farmers and/or those using biomass crops would also be able to employ other workers to gather, transport and store the feedstocks (Moore and Karlen, 2013).

\subsection{Double Cropping as Weed Suppression}

Mono-cropping of sorghum is traditional practice by small holders in Eastern Hararghe zone which worsens the infestation of striga and required to undertake research on cropping system for make the farmers less exposed to current changing weather (Fuad et al., 2017). Whereas double cropping is 
used as weed suppressing in different ways; one the weed has no get gap to emerge above the soil due to the second crop is planted immediately after the first crop is harvested. Besides most weed species adapted to degrade soil, with low organic matter, low Nitrogen and low in other important nutrients content in general. However, double cropping with legumes crop enhances soil fertility by building organic matter in the soil and crops get opportunity to resist parasitic weed.

\subsection{Suitable Agroecology for Double Cropping Sorghum in Ethiopia}

In Ethiopia, drought can be addressed by developing drought tolerant and high yielding improved varieties while addressing the plant biomass necessity is one of the strategies in the sorghum breeding program in moisture stress areas (Amare et al., 2020). In some parts of the moisture stress areas, there are two different planting opportunities depending on the timing of rain (Figure3). Most farmers traditionally plant late-maturing landraces in April after 3-4 rain showers and harvest in November. Farmers plant early maturing genotypes in July and harvest in November (Alemu, 2018). In the North Wollo, South Wollo and Oromia Special zones farmers relay on their sorghum and tef crops. The main crop production period occurs during summer ('meher') season during the months of April to December. In some areas double cropping is a common farming practice as a result of effective rainfall in the months of January, February and March, which is usually known as the spring ('belg') season (Solomon et al., 2017).
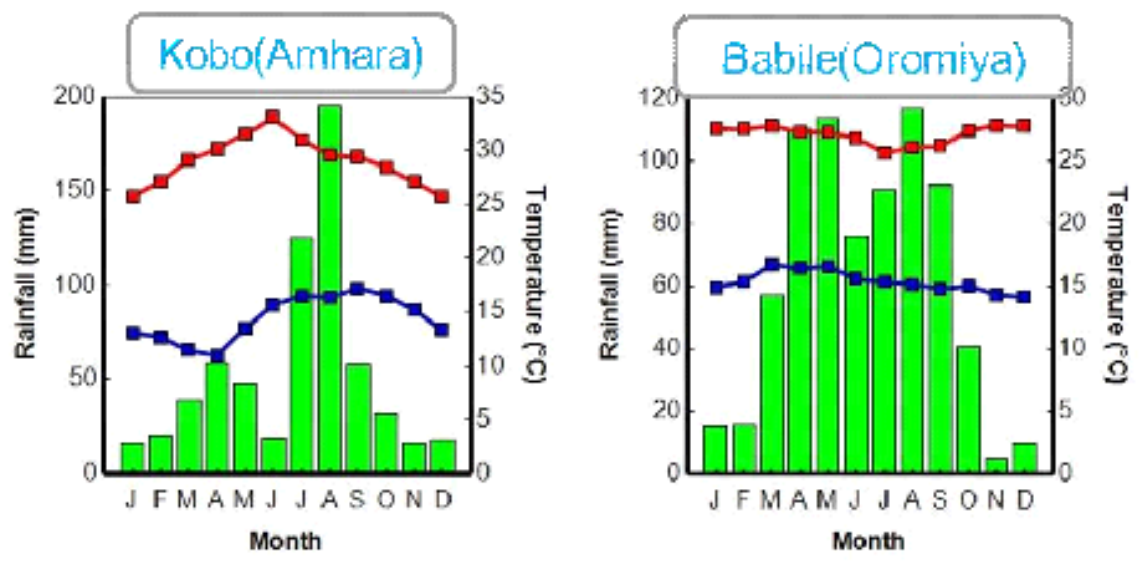

Source: Alemu, 2018

Figure 3: Bimodal monthly rainfall pattern (filled bars) and maximum and minimum temperatures (red and blue symbols) in representative dry lowland sorghum growing environments of Ethiopia: Kobo in Amhara region (A), and Babile in Oromia Region (B).

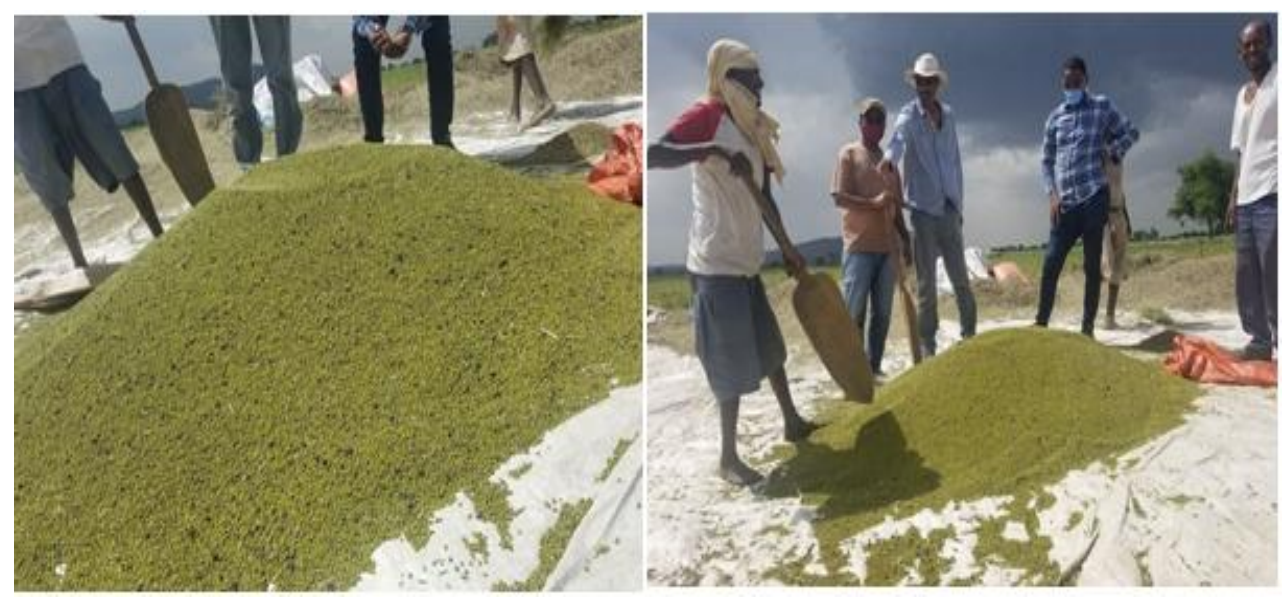

Source: Ethiopian Institute of Agricultural Research (EIAR), June 25, 2020

Figure4. Mung bean production at Mieso woreda in Ethiopia, 2020.

Melkassa and Chiro Agricultural Research Centers harvested Mung bean from large scale demonstration of a double cropping system with Sorghum at Mieso Woreda in 2020 and Sorghum planting is ready to follow mung bean harvesting (Figure 4). Mieso district is one of the areas of 
Western Haraghe that is persistently exaggerated by moisture stress though the area is well known for its sorghum production. The area has bimodal rainfall but both seasons have growing days of slightly less than 3 months. From the start of season analysis the planting dates form March - May season and July to September season (Gelana and Berhanu, 2019).

\subsection{Cultural Practices in Sorghum Double Cropping System}

Early sowing with a late maturing type versus late sowing with an early maturing type delivers evidence not previously offered for farmers and government about the choice of the system. There was a trade-off among biomass and grain yield across the two systems. In regions such as Oromia with a strong bi-modal rainfall pattern, and where sorghum grain and stover are equally essential in the mixed crop-livestock farming system (Alemu, 2018). Farmers in Fedis area are adapted to sow the local varieties from end of March to the middle of April. Farmers do not need to leave their land idle when the rain starts early in March/April until the right planting time of the early maturing sorghum varieties which plant from middle of June to the beginning of July. Consequently, the farmers in a dilemma whether to sow early at the onset of rainfall or leave their land idle until the time of sowing for early maturing sorghum varieties (Fuad et al., 2017). Therefore, to improve this problem by undertake research on cropping system is mandatory which help the farmer by associating familiarized cropping system and untimely sorghum planting practice with double cropping of improved and early maturing crop varieties with mung bean or legumes crop.One of the simplest double cropping strategies for producers to adopt would be to plant a mung bean crop in the spring and harvest it for sorghum the following mean season summer. The legume crop would be the primary crop in this sequence because of the mung bean crop early to maturing. Management of the mung bean does not require complex management strategy for farmers.

A major worry with the practice of bioenergy crops is that they may shift food crops, and have negative effects on food availability and costs. Double crop systems that consist of both a food crop and a bioenergy crop could decrease the potential of this happening (Moore and Karlen, 2013).

\subsection{Factors Required Consideration During Double Cropping System}

Planting date significantly influenced the major characters of the summer crop, but not greatly those in the spring crop. In a double cropping system for attain a high grain yield planting early in April and late in July or early in August is recommended for spring and summer crops respectively (Can and Yoshida,1999). Establishment and management costs related with the second crop must be measured in relation to any advantage in production (Moore and Karlen, 2013).

The markets stable, could be considered in double crop production systems (Moore and Karlen, 2013). Low adoption of agricultural technology is the main reasons for low farm productivity and high occurrence of poverty and food insecurity in sub-Saharan countries. Market participation will increase returns from accessible resources and profitability of the sorghum enterprise and will therefore increase adoption. Demonstrating the superiority of improved sorghum varieties will have a more real outcome (Kalibaet al., 2018).

The cultivating periods of the two crops do not overlap because of the loss of dry matter accumulation during the time in which the more productive crop is well adapted diminishes overall productivity. Under these conditions, the gain in yield obtained from the second crop can be offset by loss of yield in the primary crop (Moore and Karlen, 2013).

\section{CONCLUSION}

This review indicates paybacks of supporting research and extension outreach to farmers that includes a broad range of sorghum cropping practices to simultaneously promote farm productivity andprofitability. Double-cropping can bring many economically and environmentally benefits to a farm. Double cropping is one strategy for producing sorghum grain yield under bio mold rain fall areas in Ethiopia, but in more locations demonstration and promotion has been limited. In addition, the currently existing sorghum double crop data for the Ethiopia locations is limited, therefore focusing and demonstrating across in all suitable environment is mandatory.

Double cropping of sorghum and Mung bean strategies must be developed in order to increase double yield production in the same land in single cropping season, but in order to be adopted by producers, 
there must be establish appropriate market system for Mung bean to make the strategies economically viable when compared with well-known grain production and marketing systems. Market system skillful linking producers' production to the emerging industries.

Appropriate planting date and early maturity variety offer the chance to advance the cropping system and crop productivity in double cropping system. However, weather can interfere with double cropping system consequently, early exploit the growing season and crops are important for better achievement. Limitations of short growing season on water and growing degree days can reduce yields of one or both crops. Producers may not be familiar with the crop use in double cropping system therefore evaluating for their net economic potential and success rate based on local climate data and demonstrating the knowledge regarding how to optimize their growth and development.

\section{REFERENCES}

[1] Alemu Tirfessa, 2018. Identifying sorghum [Sorghum bicolor (L.) Moench] plant types adapted to moisture stress areas of Ethiopia.The University of Queensland, Australian.

[2] Amare Seyoum, Amare Nega, KedanemaryamWagaw, Taye Tadesse, Diriba Tadesse, Alemu Tirfessa, Habte Nida, AdaneGebereyhones, SewmehoneSiraw, TsegayeGebremariam, ChalachewEndalamaw, Hailemariam Solomon, TamiratBejiga, TokumaLegesse, David Jordan, Emma Mace, Daniel Nadew, LigabaAyele and MeronBogale, 2020.Multi environment and spatial analysis of early maturing sorghum [Sorghum bicolor (L.) Moench] genotypes in dry lowland areas of Ethiopia.African Journal of Agricultural Research15(2):278-290.

[3] Borchers, Allison, Elizabeth Truex-Powell, Steven Wallander, and Cynthia Nickerson, 2014. MultiCropping Practices: Recent Trends in Double Cropping, EIB-125. U.S. Department of Agriculture, Economic Research Service. http://www.ers.usda.gov/publications/eib-economic-information-bulletin/eib125.aspx

[4] Can Nguyen Duy\& Yoshida Tomohiko, (1999).Grain Yield of Sorghum Cultivars in a Double Cropping System, Plant Production Science, 2:2, 121-124, DOI: 10.1626/ pps.2.121.

[5] Christina Tonitto, Jacob E. Ricker-Gilbert. Nutrient management in African sorghum cropping systems: applying meta-analysis to assess yield and profitability. Agronomy for Sustainable Development, Springer Verlag/EDP Sciences/INRA, 2016, 36 (1), pp.10. Ff10.1007/s13593-015-0336-8ff. ffhal01532400f.

[6] Fuad Abduselam, Tamado Tana, Jamal Abdulahi, Habte Nida, Taye Tadese, 2017. Evaluation of Double Cropping System for Sorghum Production at Fedis, Eastern Ethiopia. Journal of Plant Sciences 5(2):7581. doi:10.11648/j.jps.20170502.15.

[7] GelanaAmente and Berhanu Mengistu, 2019. Climate Pattern and Recurrent Drought of Mieso Area, West Hararghe, Ethiopia. Merit Research Journal of Microbiology and Biological Sciences 7(2):008-026.

[8] KalibaAloyce R, Kizito Mazvimavi, Theresia L Gregory, Frida M Mgonja and Mary Mgonja, 2018. Factors affecting adoption of improved sorghum varieties in Tanzania under information andcapital constraints.Agricultural and Food Economics6 (18):1-2lhttps://doi.org/10.1186/s40100-018-0114-4.

[9] Kinde Lamessa, Sharma J.J and Taye Tessema(2015).Influence of Cowpea and Soybean Intercropping Pattern and Time of Planting on Yield and Gross Monetary Value of Sorghum.Science, Technology and Arts Research Journal4(3): 38-46.

[10] Koji Yamane, Atsuyoshilkoma\&Moriolijima, 2016. Performance of double cropping and relay intercropping for black soybean production in small-scale farms.Plant Production Science, 19:4, 449-457, DOI: $10.1080 / 1343943 X .2016 .1164574$

[11] Moore, Kenneth J. and Karlen, Douglas L., 2013. "Double cropping opportunities for biomass crops in the north central USA". Publications from USDA-ARS / UNL Faculty. 1647.4(6), 605-615. https:// digitalcommons.unl.edu/usdaarsfacpub/1647

[12] Solomon Assefa Derese, Hussein Shimelis, Mark Laing \&Fentahum Mengistu, 2017. The impact of drought on sorghum production, and farmer's varietal and trait preferences, in the north eastern Ethiopia: implications for breeding. Acta Agriculturae Scandinavica, Section B - Soil \& Plant Science, DOI: 10.1080/09064710.2017.1418018.

[13] Thomason Wade, Bee KhimChim, David Holshouser, Harry Behl, Maria Balota, Kang Xia, William Frame, and Tyler Black, 2017.Comparison of Full-Season and Double-Crop Soybean and Grain Sorghum 
Progress in Double Cropping System of Sorghum in Ethiopia: A Review Article

Systems in Central and Southeastern Virginia.Agronomy Journal 109(4):1532-1539 doi:10.2134/agronj2016.10.0577.

[14] Wilhelm WW, Hess JR, Karlen DL et al. 2010. Balancing limiting factors and economic drivers for sustainable midwestern US agricultural residue feedstock supplies. Industrial Biotechnology 6(5), 271287.

Citation: TamiratBejiga, Temesgen Teressa, Progress in Double Cropping System of Sorghum in Ethiopia: A Review Article. International Journal of Research Studies in Agricultural Sciences (IJRSAS), 2021; 7(3), pp. 22-28, https://doi.org/10.20431/2454-6224.0703003.

Copyright: (C) 2021 Authors. This is an open-access article distributed under the terms of the Creative Commons Attribution License, which permits unrestricted use, distribution, and reproduction in any medium, provided the original author and source are credited. 